\title{
Monet's Painting under the Microscope
}

\author{
Paula Dredge, ${ }^{1}$ Richard Wuhrer, ${ }^{2 \star}$ and Matthew R. Phillips ${ }^{2}$ \\ ${ }^{1}$ Art Gallery of New South Wales, Art Gallery Road, The Domain, Sydney, NSW, 2000, Australia \\ ${ }^{2}$ University of Technology, Sydney, Microstructural Analysis Unit, P.O. Box 123, Broadway, NSW, 2007, Australia
}

\begin{abstract}
An oil painting by Claude Monet, Port-Goulphar, Belle-Ile 1887 (collection of the Art Gallery of New South Wales), was examined to determine both the identity of the pigments used by the artist in this painting and his technique of mixing colors and laying paint on the canvas. The extremely complex construction of the painting was revealed by optical microscopy, scanning electron microscopy (SEM), energy dispersive X-ray analysis (EDS), and X-ray mapping (XRM) analysis of cross sections of paint flakes excised from damaged regions of Port-Goulphar, Belle-Ile. Nine different pigments were found on the painting. Many of the identified colors were modern pigments that became available only late in the 19th century as a result of scientific advances in pigment chemistry. Although similar colors were available in a natural mineral form, they lacked the vivid color of their manufactured counterparts. The use of these new synthetic metallic oxide colors by Monet accounts for the brilliance of his paintings. In addition, a separation between successive paint layers was observed in some areas of paint chip cross sections, indicating that oil-based paint was applied to paint that had dried, and consequently, Port-Goulphar, Belle-Ile was painted over a long period of time. This observation is contrary to the general perception of Monet's technique of painting freely and quickly.
\end{abstract}

Key words: Claude Monet, optical microscopy, scanning electron microscopy, energy dispersive spectroscopy, $\mathrm{X}$-ray mapping

\section{INTRODUCTION}

The Art Gallery of New South Wales is conducting a comparative study of the painting techniques of Claude Monet (1840-1926), John Russell (1858-1930), and Henri Matisse (1869-1954). This work has focused on two artistic encounters between these three painters; the first in 1886, when John Russell met Claude Monet while they were both painting at Belle-Ile, an island in Brittany off the northwest coast of France, and the second in 1896-1897, when the young Matisse visited Belle-Ile and was befriended by John Russell,

Received September 27, 2002; accepted April 16, 2002.

${ }^{*}$ Corresponding author. E-mail: Richard.Wuhrer@uts.edu.au who moved permanently to the island in 1887 . The aim of our on-going study is to determine if these two encounters between the painters influenced the painting style and technique of each painter.

The Art Gallery of New South Wales has a number of works by John Russell in its collection which have been previously studied, as well as a painting by Claude Monet, Port-Goulphar, Belle-Ile (Fig. 1). It is this painting by Monet which is the subject of this collaborative research project by the authors.

Energy dispersive X-ray spectrometry (EDS) is an established technique for the analysis of the chemical composition of paint layers in a scanning electron microscope (SEM). X-ray mapping (XRM) is the collection of character- 


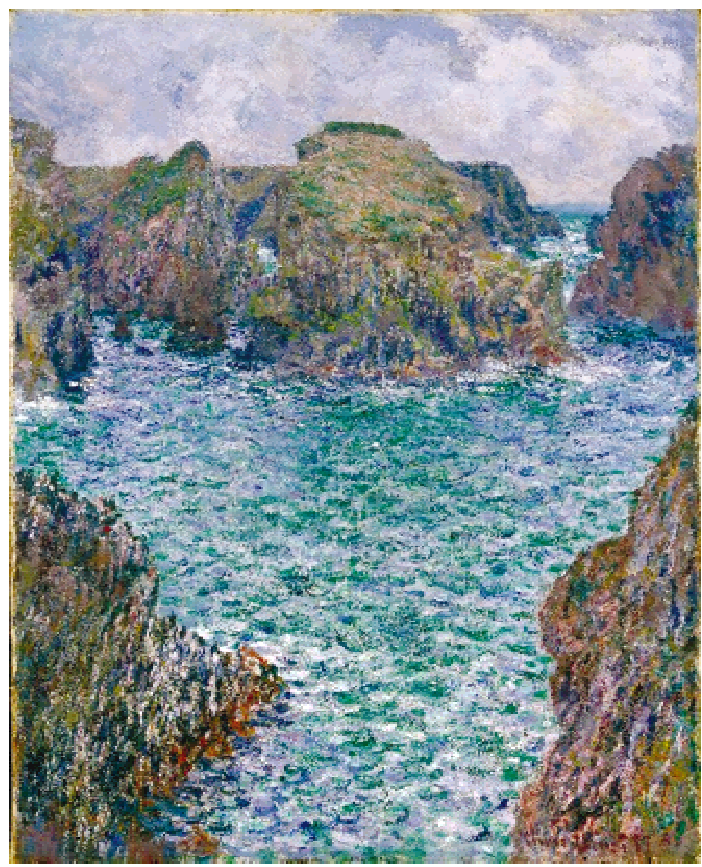

Figure 1

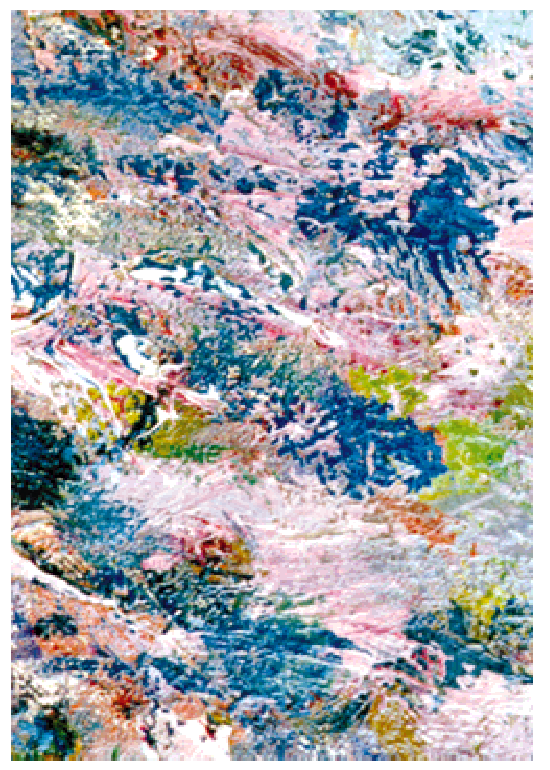

Figure 2

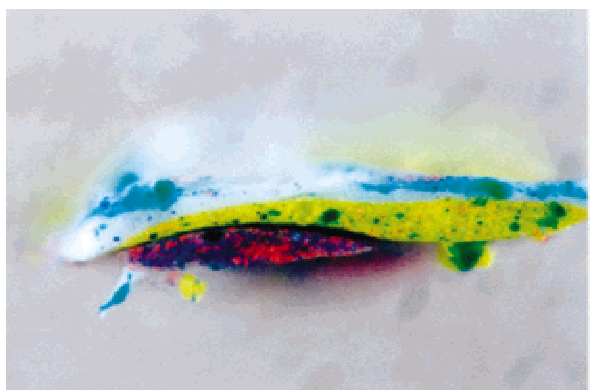

Figure 3

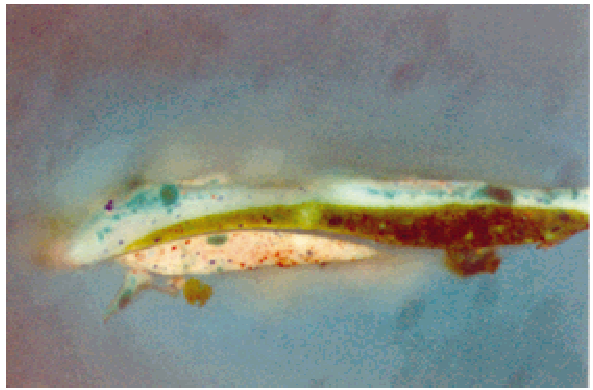

Figure 4
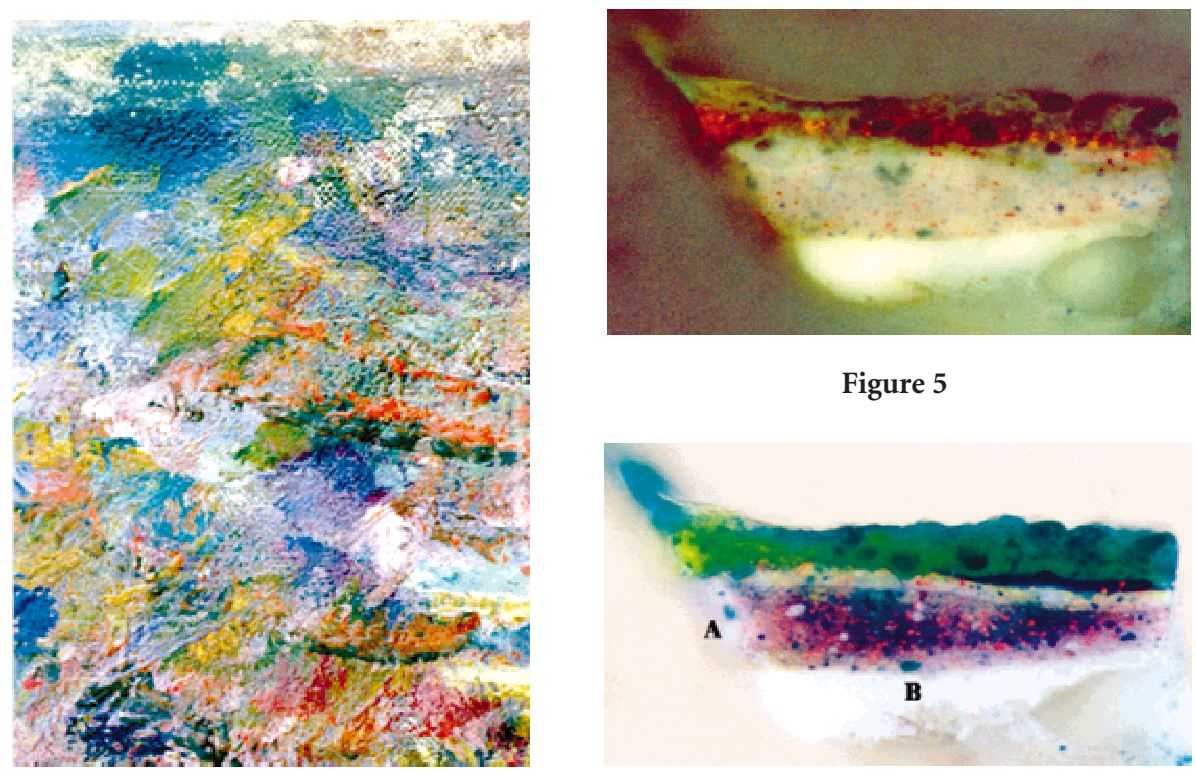

Figure 5

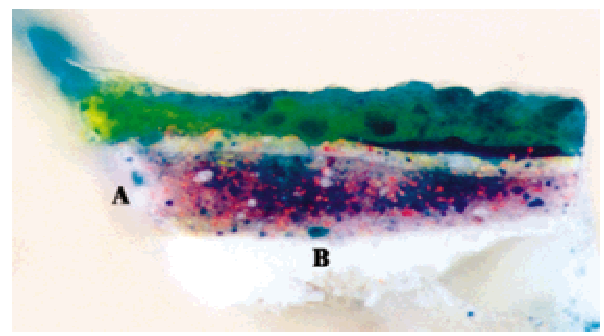

Figure 6

Figure 1. Port-Goulphar, Belle-Ile painted by Claude Monet in 1887 from the collection of the Art Gallery of New South Wales.

Figure 2. A magnified section of the lower right-hand side of the painting in Figure 1 showing the complexity of color used by Monet in this painting.

Figure 3. Optical micrograph with visible incident illumination of the cross section of a paint chip excised from the rock in the lower right-hand corner of the painting in Figure 1. Width of field is $360 \mu \mathrm{m}$.

Figure 4. Optical micrograph of the same paint chip in Figure 3 with ultraviolet incident illumination. Width of field is $360 \mu \mathrm{m}$. 
istic $\mathrm{X}$ rays as a function of the position of the scanning electron beam on the specimen. This analysis provides a high magnification image related to the distribution and relative abundance of elements within a given specimen. This capability makes X-ray mapping particularly useful to (i) identify the location of individual paint layers, and (ii) map the spatial distribution of specific paint pigments within each layer.

\section{Materials and Methods}

\section{Sample Preparation}

Samples of the painting were taken from the edges of preexisting damaged regions. Tiny paint chips (approximately $400 \mu \mathrm{m}$ in diameter) were embedded in polyester resin (Struers Serifix), matching the hardness of an aged oil paint film. These were sectioned with a microtome to reveal a cross section through all the paint layers.

\section{Optical Microscopy}

A high magnification light microscopy image (Fig. 2) of the lower-right area of the Port-Goulphar, Belle-Ile reveals the enormous variety of color within a small area of the painting. The exposed sections were examined by optical microscopy under both incident visible and ultraviolet illumination (Leitz Laborlux 12 Pol X; see Figs. 3 to 6).

The light microscopy study shows that some colors are mixed from a number of different pigments, while others are laid onto the canvas straight from the paint tube. For example, under normal visible (incident illumination) microscopy, the two types of blue used by Monet cannot be distinguished (Fig. 5). However, through the use of ultraviolet illumination, the two types of blue can be distinguished due to each blue pigment having its own characteristic fluorescence. For example, in Figure 6, French ultramarine appears very dark (area A), while cobalt blue appears pale in color (area B).

\section{Scanning Electron Microscopy and Energy Dispersive X-Ray Analysis}

Prior to imaging and analysis in the SEM, the microtomed resin blocks containing the cross section of each paint chip were coated with $30 \mathrm{~nm}$ of carbon to prevent localized charging under the electron beam, using a Balzers CEA010 carbon thread evaporation attachment connected to a Balzers SCD020 sputter coating unit.

Each specimen was analyzed using a JEOL 6300F field emission gun (FEG) SEM equipped with a thin window Kevex light element EDS X-ray detector with Moran Scientific X-ray analysis and mapping system. Backscattered electron mode imaging at $25 \mathrm{kV}$ was used to locate each paint layer as well as the various pigments within each layer. Quantitative EDS spot-mode X-ray analysis was used to identify each pigment type (Feller, 1986; Fitzhugh, 1997; Roy, 1993).

All X-ray maps were acquired at $25 \mathrm{kV}$ in the JEOL 6300 FEG SEM. The beam current was set at $0.15 \mathrm{nA}$, providing a total X-ray count rate of $3000 \mathrm{cps}$. The FEG tip was "flashed" (cleaned) and allowed to stabilize for $20 \mathrm{~min}$ prior to the collection of each map. The probe current was measured before and after each X-ray acquisition to ensure that a relative change of less than $10 \%$ in the beam current was observed. X-ray maps were collected with $256 \times 256$ pixel resolution and a dwell time per pixel of $100 \mathrm{~ms}$ to obtain good counting statistics within the required beam stability requirement.

\section{Results And Discussion}

An optical image (visible incident illumination) of the cross section of the Monet painting sample is shown in Figure 3. The optical cross section reveals that this section of painting was painted by applying wet paint over dry paint, as revealed by the separation at the interface between the two

Figure 5. Optical micrograph with visible incident illumination of the cross section of a paint chip excised from the rock in the lower right-hand corner of the painting in Figure 1 from a region close to the paint flake in Figure 3. Note the noticeable difference in pigment distribution. Width of field is $360 \mu \mathrm{m}$.

Figure 6. Optical micrograph of the same paint chip in Figure 5 with ultraviolet incident illumination. Utraviolet illumination shows the presence of two different blue pigments, French ultramarine (region A) and cobalt blue (region B). Width of field is $360 \mu \mathrm{m}$. 


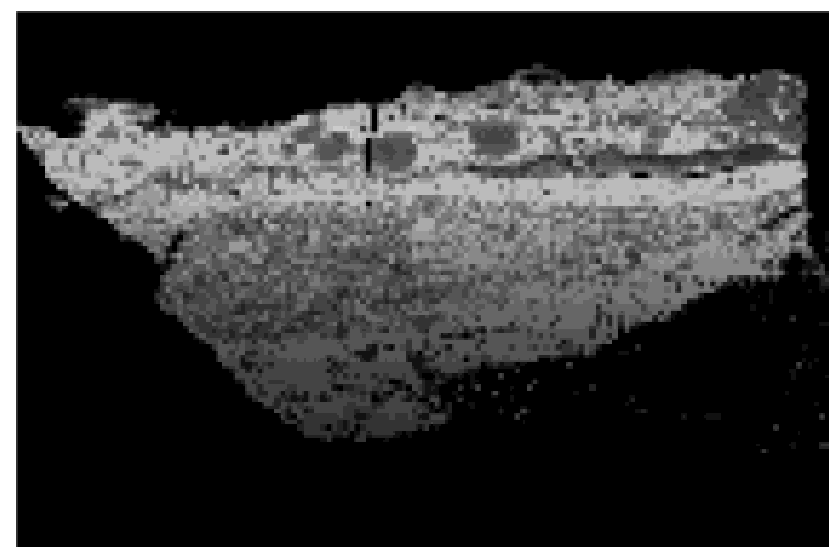

Figure 7. A backscattered electron image of the paint chip cross section excised from the lower right-hand corner of the painting showing the abundance of pigments used by Monet in this work. Width of field is $340 \mu \mathrm{m}$.

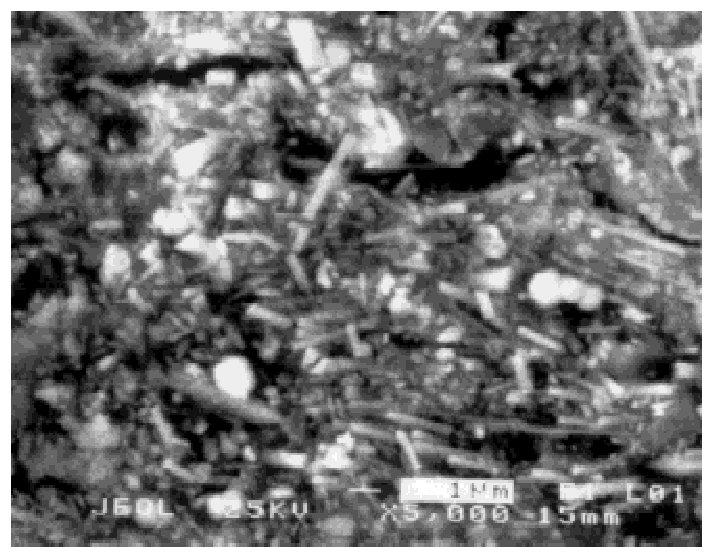

Figure 8. Backscattered electron image of a yellow section of the painting containing a rodlike pigment known as chrome yellow, a lead chromate $\left(\mathrm{PbCrO}_{4}\right.$ and $\left.\mathrm{PbCrO}_{4} \cdot \mathrm{PbSO}_{4}\right)$. Width of field $23 \mu \mathrm{m}$.

layers. This observation indicates that Monet worked on this painting over a long period of time, as oil paints take a long time to dry, and this is contrary to the generally held belief that Monet painted quickly and freely. However, the optical images (Figs. 3, 4, 5, and 6) also show regions with no separation between the paint layers, indicating that these areas were painted wet paint over wet paint, while mixing the paints directly on the canvas.

A SEM backscattered electron image (Fig. 7) of a paint cross section shows the abundance of pigments used within a small section of painting. A high magnification backscattered electron image of a yellow region of the painting reveals that the areas contain rod-like pigments (Fig. 8), which contain lead, chromium, and oxygen. This pigment is known as chrome yellow, a lead chromate $\left(\mathrm{PbCrO}_{4}\right.$ and $\mathrm{PbCrO}_{4}$. $\mathrm{PbSO}_{4}$ ). Interestingly, the chrome yellow pigment was replaced by cadmium yellow late in the 19th century. However, Port-Goulphar, Belle-Ile seems to have a mixture (blended) of the two types of yellow pigment (chrome and cadmium).

Background corrected X-ray maps for aluminium, silicon, calcium, chromium, cobalt, copper, cadmium, mercury, and lead from a representative paint chip are shown in Figure 9. These maps, as well as extensive spot mode EDS analysis, were used to identity the following pigments: lead white [basic lead carbonate $2 \mathrm{PbCO}_{3} \cdot \mathrm{Pb}(\mathrm{OH})_{2}$ ], vermilion [mercuric sulphide $\mathrm{HgS}$ ], cadmium yellow [cadmium sulfide CdS], chrome yellow [lead chromate $\mathrm{PbCrO}_{4}$ and $\mathrm{PbCrO}_{4} \cdot \mathrm{PbSO}_{4}$ ], viridian [hydrated chromium oxide $\mathrm{Cr}_{2} \mathrm{O}_{3} \cdot 2 \mathrm{H}_{2} \mathrm{O}$ or $\mathrm{Cr}_{2} \mathrm{O}(\mathrm{OH})_{4}$ ], emerald green [copper acetoarsenite $3 \mathrm{Cu}\left(\mathrm{AsO}_{2}\right)_{2} \cdot \mathrm{Cu}\left(\mathrm{CH}_{3} \mathrm{COO}\right)_{2}$ ], cobalt blue [cobalt aluminate $\mathrm{CoO} \cdot \mathrm{Al}_{2} \mathrm{O}_{3}$ ], and French ultramarine [approximately $\mathrm{Na}_{6-10} \mathrm{Al}_{6} \mathrm{Si}_{6} \mathrm{O}_{24} \mathrm{~S}_{2-4}$ ]. The complex distribution of these pigments within a paint chip cross section from the painting is shown in Figure 10.

Two organic lake colors (a dye precipitated onto an inert base) were also found in Port-Goulphar, Belle-Ile; a red lake (presumably madder) on an aluminium hydroxide base, and a yellow lake (unidentified) on a base of natural chalk sphericals.

This present work shows that Monet worked on PortGoulphar, Belle-Ile with a limited number of pigments; two reds, three yellows (the yellow lake may be an impurity added by the color merchant to enhance the color of the cadmium yellow), two blues, two greens, and white. These pigments were premixed in an impressive number of combinations to give enormous variation in color on the painting. Some single brush strokes, such as those in the dark rocks, contained all 10 pigments mixed together. Subtle variations in color were achieved by slight alterations in the proportions of each pigment in the paint mix.

\section{CONCLUSIONS}

The combination of these microscopy methods used in this study enabled (a) the identification of each of the pigment types used in the painting, and (b) an insight into the paint application techniques used by Monet, in particular whether the paint was premixed or applied pure from the tube and mixed wet-in-wet on the canvas. The complex construction of the paint layers studied in this work confirmed that 


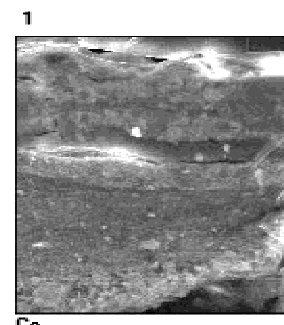

Co
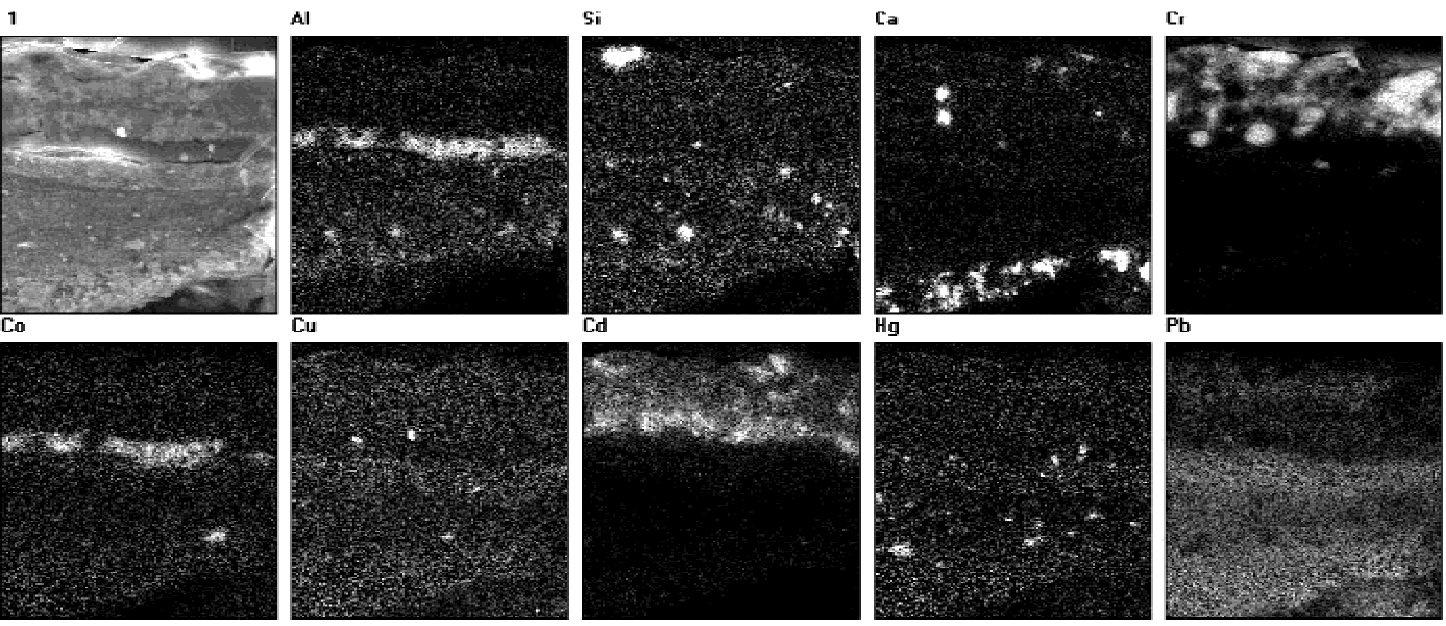

Figure 9. X-ray maps (XRM) for aluminum, silicon, calcium, chromium, cobalt, copper, cadmium, mercury, and lead from a representative paint chip cross section. Maps were collected at an accelerating voltage of $25 \mathrm{kV}$, beam current of $0.15 \mathrm{nA}, 256 \times 256$ pixels and a dwell time per pixel of $100 \mathrm{~ms}$. Width of field, $110 \mu \mathrm{m}$.

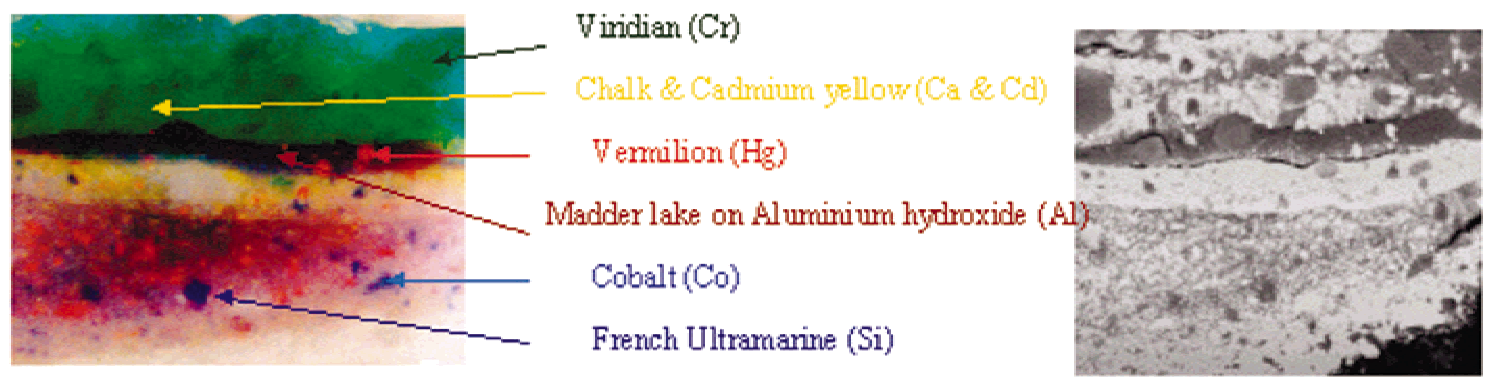

Figure 10. Optical micrograph image showing the complex distribution of pigments identified using EDS spot mode analysis. Width of field $50 \mu \mathrm{m}$.

Monet possessed a mastery of color through a deep understanding of the pigments available at that time. In addition, contrary to popular belief, certain sections of Port-Goulphar, Belle-Ile were painted over intervals long enough for the previously painted area to dry.

\section{ACKNOWLEDGMENTS}

The authors gratefully acknowledge the Art Gallery of New South Wales and the University of Technology, Sydney for their support.

\section{REFERENCES}

Feller, R.L. (ED.). (1986). Artists' Pigments. A Handbook of Their History and Characteristics, vol 1. Washington, D.C.: National Gallery of Art.

Fitzhugh E.W. (Ed.). (1997). Artists' Pigments. A Handbook of Their History and Characteristics, vol 3. Washington, D.C.: National Gallery of Art.

Roy, A. (ED.) (1993). Artists' Pigments. A Handbook of Their History and Characteristics, vol 2. Washington, D.C.: National Gallery of Art. 


\section{THOMSON}

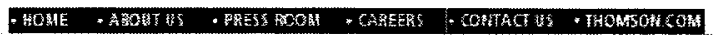

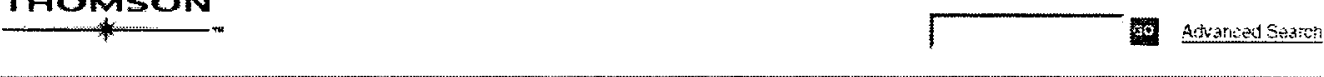

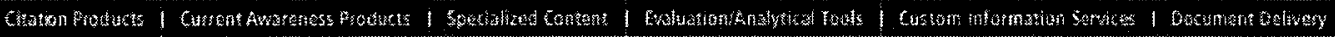

Fis

Hatarac

Goweknikele

GON PROFI

CORPORATE

PRODUCTS
CONFEREMGES AWOS EVEATS

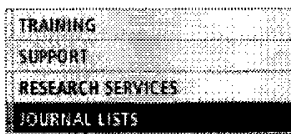

BO LRARAL LITTS
TOURMAL SELECION FROCESS

(c) unus

ISI Essars

HOT BESEASCH

Gerions

Business Webste 4 पy
SEARCH RESULTS

$$
\begin{aligned}
& \text { ISI Master Jounal List } \\
& \text { SEARCH RESULTS }
\end{aligned}
$$

SEatch Terms: 1431-9270

Totat foumals tount: 1

The folbwilg tite(s) matched your request

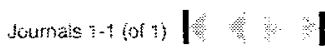

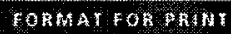

MLFOSCOPY AND MCROARAALYSIS

Bimontity

S8ㄴ: 1431.9276

CAMBRIOGE UNIV PRESS, 4O WEST ZOTH ST, NEN YORK. USA. WY, YOOY HAE

joumats:-1:at: $1 \leqslant 1$

FORMAT FOR PRINT 